ISSN 0001-6012/2019/61/4/166-171 Acta Médica Costarricense, (C) 2019 Colegio de Médicos y Cirujanos de Costa Rica

\title{
Original
}

\section{Adverse outcomes of frailty in the older population of Costa Rica}

\section{(Eventos adversos de la Fragilidad en la población adulta mayor de Costa Rica)}

José E. Picado-Ovares, ${ }^{1,2}$ Isabel C. Barrientos-Calvo, 1,2 Fernando Morales-Martínez, ${ }^{1,2}$ Alejandro Sandí-Jirón²

\section{Resumen}

Objetivo: Entre los años del 2000 y 2050 el número de habitantes mayores de 60 años de edad en en Costa Rica se duplicarán. Un número considerable de ellos llegarán a ser frágiles. Estudios han demostrado la relación entre la condición de fragilidad y pobres desenlaces. El objetivo del presente trabajo fue identificar los eventos adversos asociados a la fragilidad en la población adulta mayor de Costa Rica.

Métodos: Para realizar el análisis, se emplea la totalidad de los casos disponibles en la base de datos del estudio de CRELES en el 2005, que pertenecen a la cohorte que da seguimiento en el periodo 2005-2009. En el año de partida de esta cohorte, se cuenta con un total de 2827 pacientes. El fenotipo de la fragilidad fue construido basado en el modelo fenotípico. Se realizó un análisis longitudinal, y se examinó los años iniciales y finales de esta cohorte. Los desenlaces analizados fueron la mortalidad, los ingresos hospitalarios, el deterioro funcional, las caídas y la autopercepción de la salud en el año 2009. Se utilizó una técnica de regresión logística multinomial, utilizando variables de desenlaces como variables dependientes. La condición de fragilidad se utilizó como variable independiente. Como resultado, se obtuvo una odds ratio para la incidencia de cada categoría de desenlaces con un $95 \%$ de confianza.

Resultados: La condición de fragilidad se asoció con mayor deterioro funcional, aumento en los ingresos hospitalarios y empeoramiento en la autopercepción de la salud.

Conclusión: La fragilidad se relacionó con pobres desenlaces en la población costarricense. La identificación de esta condición proporciona una oportunidad para una intervención temprana.

Authors names and affiliations: 'Hospital Nacional de Geriatría y Gerontología, San José, Costa Rica. ${ }^{2}$ Universidad de Costa Rica, San Pedro, San José, Costa Rica. Abbreviations: Costa Rica Estudio de Longevidad y Envejecimiento Saludable, CRELES.

Conflicts of interest, sources of support or financial aids: The authors declare no conflict of interest statement or any financial or personal relationships or aids with other people or organizations that could inappropriately influence (bias) our work. The authors use a public database. 凶jepicado@ccss.sa.cr 
was used as an independent variable. As a result, there was an odds ratio obtained for the incidence of each outcome category with $95 \%$ confidence.

Results: Frailty was associated with functional declines, hospital admittances, and worsening of the self-perception.

Conclusion: Frailty was related to adverse outcomes in Costa Rica. Identifying this provides an opportunity for an early intervention.

Keywords: frailty, outcomes, incidence, elderly, older population.

Fecha recibido: 06 de diciembre 2019

Fecha aprobado: 22 de agosto 2019

Between 2000 and 2050 the number of inhabitants aged 60 years or older in the World and in Costa Rica will double*. A considerable number of them will become frail. Frailty is considered a clinical state in which there is an increase in an individual's vulnerability for developing increased dependency and/or mortality when exposed to a stressor. ${ }^{1,2}$

Although the operational definition of frailty is controversial, two approaches to defining frailty are widely accepted. ${ }^{2}$ The deficit model, which consists of adding an individual's number of impairments and conditions to create a frailty index, and the second model, the phenotype model, which describes frailty as a clinical syndrome resulting from a combination of variables, such as weight loss, fatigue, weakness, diminished gait speed, and poor physical activity that reflects an underlying physiologic state of multisystem dysregulation. ${ }^{1,3}$

Multiple population studies have shown the relationship between frailty and poor outcomes, such as increased mortality rates, hospital admittances, functional decline, falls, fractures, and others, ${ }^{4}$ and some of these studies have been performed in Latin American populations and Costa Rica. ${ }^{4-10}$ The present study's objective was to identify the adverse outcomes of frailty (using the phenotype model) in the older Costa Rican population after a 4-year follow-up.

\section{Methods}

\section{CRELES Study}

A longitudinal study design was established using the Costa Rican Longevity and Health Aging Study (CRELES) study, which is a dataset of Costa Rican older adults born in or before 1946; it included a representative sample of $\geq 60$-year-old adults from Costa Rica. A full description of sampling methods may be found elsewhere ${ }^{\star \star}$. For the purpose of this report, data from the first (2005) and third (2009) waves were used. Both interviews assessed the same information, with the exception of mortality data in 2009, including a next-of-kin interview for the deceased participants. The research protocol of CRELES was approved ethical science committee of the University of Costa Rica in the March 17, 2004 session (reference: VI-763-CEC-23 -04), research project number 828-A2 -825.

\section{Construction of the frailty variable}

The frailty indicator is constructed based on the five variables from Fried's phenotypical model ${ }^{3}$ with certain modifications. This model is one of the most used to study this condition and is first used in the population in Costa Rica. The variables were built as follows:

Weakness: the measurement of the grip strength was used. It was performed with a dynamometer in the CRELES study. The older people were asked to extend his or her dominant arm to full length alongside his or her body, and when instructed by the interviewer, the person was to grip the handle with all his or her strength and immediately loosen the grip. Then, he or she would rest for 3 minutes, repeating the test for a second time. The result of the second grip strength test was used for this study.

A regression model was calculated in which hand strength was the dependent variable and the independent variables were sex and body mass index. Then, the residual values were added to the adjusted average value to create a standardized grip strength variable. The $20^{\text {th }}$ percentile was calculated, resulting in a cut-off value. The patient was considered to have an altered grip strength test if his or her result was below the $20^{\text {th }}$ percentile or could not perform the test at all.

Slowness: the variable of gait speed was used. The information was obtained from the stand-up and walk test. This test consists of asking the person to stand-up from a chair and walk at his

*(World Health Organization. World Report on Ageing and Health http://apps.who.int/iris/bitstream/10665/186471/1/WHO_FWC_ ALC_15.01_spa.pdf?ua=1, 2015 (accessed on December 10 2017).

${ }^{* *}$ (Rosero-Bixby, Luis, Xinia Fernández, William H. Dow. CRELES: Costa Rican Longevity and Healthy Aging Study, 2005 (Costa Rica Estudio de Longevidad y Envejecimiento Saludable) [Computer file]. ICPSR26681-v1. Ann Arbor, MI: Inter-university Consortium for Political and Social Research [distributor], 2010-07-21. doi:10.3886/ICPSR26681 http://ccp.ucr.ac.cr/index.php/creles-inicio.html (accessed on December del 2017) 
or her usual rhythm for a distance of 3 metres. This distance was divided by the elapsed time, resulting in the speed of the individual. Afterwards, a regression model was adjusted where the dependent variable was the calculated speed and the independent variables were height and sex, obtained from the CRELES database. The predicted values were calculated, and an average value was obtained. The residual values were added to this average value, which resulted in a new speed variable from which the $20^{\text {th }}$ percentile was calculated.

An altered gait speed was considered if one of the following conditions was present: the patient had a gait speed lower than the $20^{\text {th }}$ percentile value, the person could not do the test at all, or if the person answered affirmatively to the question: "Do you have a problem that prevents you from doing any mobility or flexibility test?"

Low level of physical activity: For this variable, the answer to the question "In the past 12 months have you had regular exercise or rigorous physical activity such as sports, jogging, dancing or heavy workloads three times a week?" was used, and it was considered altered physical activity if the question was answered in the negative.

Exhaustion or poor endurance: The answer to the question, "Were you full of energy?", was used. The variable was considered altered if the older people responded that they felt they had no energy whatsoever.

Weight loss: We used the answer to the question, "In the last 6 months, have you lost more than 5 kilograms of weight without planning it?". If the patient answered affirmatively, the variable was considered altered.

Once the five variables were defined, each was codified as 1 if they met the frailty criteria for a particular variable and 0 if the criteria was not met. Those who did not present altered variables on any of the 5 measures analysed (which translates to a total sum of 0 for all variables) were classified as robust, those who presented 1 or 2 altered variables were classified as pre-frail, and those who presented 3 to 5 altered variables were classified as frail. It is worth mentioning that if any values were missing, the individual was not included, as there was a strict method to prevent biases for this categorization. This methodology was also used for the cohort follow-up years in 2005, 2007, and 2009.

For this study, we measured the incidence of some outcomes analysed in other publications. The year 2005 was considered the beginning year of the longitudinal analysis, and the year 2009 was the final follow-up year of the cohort. The specifications for these outcomes are described as follow:

Mortality: This variable was registered in the mortality database of the CRELES study according to the year.

Hospital admittance: For this outcome, the questions "Were you admitted to a hospital?" and "For the past 12 months, how many nights did you spend in the hospital?" were used. A variable was created based on the answers, and two categories were established: those who were admitted one or more times and those who were not admitted at all for the years analysed.

Functional decline: To create this variable, the older people were asked if he or she had difficulty doing any of the following 6 activities: walking, climbing flight of stairs, bathing, feeding, going to the bathroom, or having faecal or urinary incontinence.

For the walking variable, the questions "Can you walk?', "Is it difficult for you to walk multiple blocks?" and/or "Is it difficult for you to cross a room walking?" were used.

For the climbing a flight of stairs variable, the question "Is it difficult for you to climb a flight of stairs without pausing or resting?" was used.

Regarding the feeding variable, the question "Do you have difficulties in feeding, cutting food, filling cups, etc.?" was considered.

The use of the bathroom variable was assessed by the answer to the question "Is it difficult for you to use the bathroom or sitting and standing up from the toilet?"

Finally, for the variables of faecal and urinary incontinence, the following questions were used: "For the past 12 months, have you had any problems on an almost daily basis with involuntary loss of urine?" or "Involuntary loss of faeces?"

The aforementioned variables were analysed in a dichotomic form so that a total sum of 0 to 6 points was established (considering 1 as a negative point and 0 as positive point for each factor). Therefore, if there were changes in functionality from 2005 to 2009, these would be reflected by the changes in the total sum of the points for each year; specifically, it was considered a functional deterioration if a person in 2009 had a higher score than that obtained in 2005.

Falls and self-perception of health: Both variables were considered just as they were answered and recorded in the CRELES database, which used the following questions: "Have you fallen any time during the past two years?" (not including falls due to drunkenness) and for the health self-perception item "How would you say your health condition is now: excellent, very good, good, regular, bad?" It is worth noting that for this last variable, the answers were considered healthy if the response was "excellent, very good and good" and unhealthy if the response was "regular or bad". By performing this grouping, the dichotomic nature of the variables was upheld for both cases.

Once the outcome variables were obtained, an analysis was made using a multinomial logistic regression; for the present study, these outcome variables were used as dependent variables and a model was built for each of the five outcomes.

With regard to the independent variables, interest was focused on how the frailty phenotype was associated with each proposed outcome. With these models, in addition to including frailty condition as an independent variable, a wide variety of 
other variables (age, gender, comorbidities, among others) were included, which were used to adjust the model estimation, and the decision to include or exclude them was made according to the criteria for variable selection.

Once an adequate model was obtained, odd ratios were calculated for the outcome categories considered least healthy (i.e., prefrail and frail). This was because the outcome category considered healthy (robust) was the one used as reference. With these odd ratios, the respective 95\% confidence intervals

\begin{tabular}{|c|c|}
\hline \multicolumn{2}{|c|}{$\begin{array}{c}\text { Table 1. Costa Rica: Prevalence of health and } \\
\text { sociodemographic characteristics of the elderly of } \\
\text { analyzed on the year } 2005^{*}\end{array}$} \\
\hline $\begin{array}{l}\text { Health and } \\
\text { sociodemographic } \\
\text { characteristics }\end{array}$ & Percentual distribution \\
\hline \multicolumn{2}{|l|}{ Age } \\
\hline $60-69$ & 53,8 \\
\hline $70-79$ & 31,6 \\
\hline $80+$ & 14,7 \\
\hline \multicolumn{2}{|l|}{ Sex } \\
\hline Female & 52,5 \\
\hline Male & 47,5 \\
\hline \multicolumn{2}{|l|}{ Education } \\
\hline$\leq 6$ to & 78,5 \\
\hline $7 \mathrm{mo}-9$ no & 7,7 \\
\hline$\geq 10 \mathrm{mo}$ & 13,8 \\
\hline \multicolumn{2}{|l|}{ **Income } \\
\hline$\leq 100$ US dollars & 41,9 \\
\hline 100-520 US dollars & 38,1 \\
\hline$\geq 520$ US dollars & 20,0 \\
\hline \multicolumn{2}{|l|}{ Physical activity } \\
\hline Yes & 31,4 \\
\hline No & 68,6 \\
\hline \multicolumn{2}{|l|}{ Live alone } \\
\hline Yes & 9,9 \\
\hline No & 90,1 \\
\hline \multicolumn{2}{|l|}{ Health self-perception } \\
\hline Healthy & 52,7 \\
\hline Unhealthy & 47,3 \\
\hline \multicolumn{2}{|c|}{$\begin{array}{l}\text { Note: The total analyzed population was } 2827 . \\
\text { *Base year. } \\
{ }^{* *} \text { 1 US dollars approx } 480 \text { colones. (2005) } \\
\text { Abbreviation: US, United State Dollars. }\end{array}$} \\
\hline
\end{tabular}

were estimated, mainly focusing on the relationship between outcome and frailty.

To carry out the analysis, all the available cases of the CRELES study database which belong to the cohort that follows in the period 2005-2009 were used. In the year of the initial cohort (2005), there was a total of 2827 patients, and counting for the final year of the cohort with 1863 patients. There are no analytical exclusion criteria because they point in the same direction as those already carried out by the CRELES study, where 525 cases were lost due to mortality and 439 because they could not be contacted to follow them.

\section{Results}

The final sample of the base year 2005 was composed of 2827 individuals with ages ranging from 60 to 109 (average of 70 years). 52,5\% were women. The sociodemographic and health characteristics of the analysed patients are summarized in tables 1 and $2.53 .8 \%$ were under the age of 69 years, $31.6 \%$ between the ages of 70 to 79 years and $14.7 \%$ presented ages from 80 or above. The education level of the study population was low, for this study $78.5 \%$ presented an education level of less than 6 years of schooling. At the economic level, $41.9 \%$ presented an income of less than 100 United State Dollars (USD) and an 20\% presented data of more than 520 USD per month. $9.9 \%$ of the analysed patients lived by themselves and a $47,3 \%$ presented a poor health perception.

Regarding comorbidities seen in the frail patients, 48,4\% has hypertension, $20.8 \%$ Diabetes, $16,7 \%$ pulmonary illness, 9.7\% osteoporosis, $14.6 \%$ arthritis, 3.8\% with cerebrovascular events, $5.9 \%$ cancer, $4.6 \%$ coronary disease and $39.6 \%$ had dyslipidaemia (table 2).

Table 2. Costa Rica: Prevalence of comorbidities of analyzed elderly on the year $2005^{*}$

\begin{tabular}{|c|c|}
\hline Variable & Percentage (\%) \\
\hline Arthritis & 14,6 \\
\hline Falls & 46,0 \\
\hline Cerebrovascular event & 3,8 \\
\hline Osteoporosis & 9,7 \\
\hline Hypertension & 48,4 \\
\hline Diabetes & 20,8 \\
\hline Cancer & 5,9 \\
\hline Pulmonary Disease & 16,7 \\
\hline Heart attack & 4,6 \\
\hline Cholesterol & 39,6 \\
\hline Smoking & 43,1 \\
\hline
\end{tabular}


For the base year 2005, the final analysis shows a prevalence of frailty in the older population of $11 \%$. The general characteristics of the frail patient in Costa Rica were analysed in a previous prevalence study ${ }^{(11)}$. Using a model based on Fried's with certain modifications, the Costa Rican prevalence of frailty in the CRELES Study for 2005 was $11.6 \%$, of prefrail $65.5 \%$ and $22.9 \%$ robust. ${ }^{11}$

From the analysed outcome variables of this Costa Rican population, frailty was associated with functional decline (OR 4,79, CI 1,89; 12,11), hospital admittance (OR 3,21, CI 1,85; 5,86 ), and worsening of the self-perception of health (OR 5,17, CI 3,45;7,75).

Frailty was not associated with increased mortality rates (OR 1,9; CI 0.87;4,2) or a higher risk of falls in the Costa Rican population (OR 1,36; CI 0,93;1,95) (Table 3).

\section{Discussion}

Although there have been studies that have measured the outcomes related to frailty in the Costa Rican population, ${ }^{10}$ this is the first study, to the knowledge of the authors, that identify these outcomes in the older Costa Rican population using the phenotype model to define frailty. In this study, frailty was associated with conditions that impact the health care systems for older people, as well as their quality of life, such as functional decline, hospital admittance, and a worsening of the self-perception of health.

Regarding the functional decline outcome, after adjusting the variables for age, hypertension, diabetes and lung disease, it was evident, as was mentioned, that there was a risk of such an outcome associated with frailty. This risk is even greater than that detected in other related epidemiological trials. ${ }^{5}$ This correlation was also observed in pre-frail patients (OR 3,27; CI $1,35 ; 7,79)$. This result matches the findings of the majority of longitudinal trials conducted around the world. ${ }^{12,13}$

The physiopathology of frailty at the central nervous, hormonal, and immune system levels directly affects the balance and homeostasis of the muscle and leads to sarcopenia ${ }^{1}$ that explains the findings of this study regarding functional deterioration and performance.
Regarding hospital admittance, after adjusting for the variables of age, lung disease, heart failure, strokes, and osteoarthritis, it was demonstrated that there were more admittances as an outcome of the frailty state. These data were similar to the original discoveries published by Fried ${ }^{3}$ and two other population trials. ${ }^{13,14}$ Similar to the findings with functional declines, the relationship between frailty and hospital admittances was higher than that demonstrated in other trials. ${ }^{6}$ This association is maintained even in pre-frail patients when compared to robust patients (OR 1,93; CI 1,64; $3,18)$.

Functional decline and increase of hospital admittances may explain the major risk of a worsening of self-perception of health related to a frail condition after adjusting for age, income, education level, diabetes, lung disease, osteoporosis, osteoarthritis, and coronary disease. This strong association was also observed in pre-frail patients (OR 2,17; CI 1,63;2,89). Despite this strong and important association, this finding has not been documented in similar studies. ${ }^{4}$

After adjusting the model, frailty was not associated with mortality or with a risk of falls in the Costa Rican population.

For the analysis performed, the main problem that emerged was the reduction of data in the years of interest (2005 and 2009) because these data mainly affect the frailty variable. Because there were missing data, some cases could not be matched where the outcomes of interest were to be analysed. These results also presented problems regarding missing data, given the nature of the longitudinal study.

Regarding mortality, these data do not match what has been observed in other longitudinal trials. Only two published studies have presented similar findings. ${ }^{14,15}$ Many records were inaccurate in their measurements or were lost; hence, there was no efficient way to determine whether the older people actually passed away or whether information was truly lost, making it necessary to exclude data from the final analysis in the model. However, the final sample analysed was sufficient and did not present a wide confidence interval.

The same happened with the variable involving falls, where the frailty condition was not a factor that led to increases the risk of falls, as has been documented by other longitudinal trials. ${ }^{5,22-24}$ However, other trials do not describe

\begin{tabular}{|c|c|c|c|c|c|c|c|c|c|c|}
\hline \multirow{2}{*}{ State of frailty ${ }^{1 /}$} & \multicolumn{2}{|c|}{ Functional decline } & \multicolumn{2}{|c|}{ Hospitalizations } & \multicolumn{2}{|c|}{ Health perception } & \multicolumn{2}{|r|}{ Falls } & \multicolumn{2}{|c|}{ Mortality } \\
\hline & OR & $\mathrm{Cl}$ & OR & $\mathrm{Cl}$ & OR & $\mathrm{Cl}$ & OR & $\mathrm{Cl}$ & OR & $\mathrm{Cl}$ \\
\hline Prefrail & 3,25 & 1,$35 ; 7,79^{*}$ & 1,93 & 1,$16 ; 3,18^{*}$ & 2,17 & 1,$63 ; 2,89^{*}$ & 1,01 & 0,$77 ; 1,33$ & 1,43 & 0,$70 ; 2,92$ \\
\hline Frail & 4,79 & 1,$89 ; 12,11^{*}$ & 3,29 & 1,$85 ; 5,86^{*}$ & 5,17 & 3,$44 ; 7,75^{*}$ & 1,36 & 0,$94 ; 1,95$ & 1,91 & 0,$87 ; 4,18$ \\
\hline \multicolumn{11}{|c|}{$\begin{array}{l}\text { " } \mathrm{p}<0,05 \text {. } \\
\mathrm{Cl}=\text { Confidence Interval at } 95 \% ; 0 \mathrm{R}=0 \mathrm{dds} \text { Ratio. } \\
\text { 1/Category of reference:" Robust". } \\
\text { Note: A model is made for each outcome by adjusting different variables. }\end{array}$} \\
\hline
\end{tabular}




\section{Consequences of frailty in Costa Rica / Picado-Ovares et al}

this relationship., 3,13-17,18-21 Reasons that explain this finding are similar to what was mentioned above.

The phenotypic model used in this study has had great support by other authors in different publications. However, its structure from sample variables from a study not originally designed for this purpose may present certain difficulties in a reliable outcome. Therefore, it can overestimate or underestimate the actual condition of frailty. The same can be said of the follow-up, since it could not corroborate to $100 \%$ the deaths, hospitalizations or other adverse results, and that could be due to accidents, other illnesses, or other reasons and not necessarily frailty.

Despite the study limitations mentioned above, the results generated do represent the Costa Rican population. Furthermore, the criteria used for this study were more similar to Fried's original criteria when compared to previous studies at the national and international levels. ${ }^{3}$

The impact of the frailty syndrome and the significant outcomes for the Costa Rican older population was demonstrated, providing an overall picture of this important condition in this area of the American continent. This allows us to assess the needs for future investigations in this area and to take preventive actions such as caloric and protein support, exercise intervention (resistance and aerobic), reduced polypharmacy, and treat Vitamin D deficiency, ${ }^{1,2}$ involving specific groups of older people to avoid the frailty syndrome and its consequences, which can affect health care systems and the quality of life for older individuals.

Frailty was associated with adverse outcomes such as a higher risks of hospital admittances, functional deterioration, and worse self-perception of health in the Costa Rican population. This risk is present even in pre-frail patients, which then represents an opportunity for an early intervention to avoid these outcomes. Frailty was not associated with higher mortality rates or with a higher number of falls.

\section{References}

1. Clegg A, Young J, Iliffe S, Rikkert MO, Rockwood K Frailty in elderly people. Lancet. 2013, 2;381:752-762.

2. Morley JE, Vellas B, van Kan GA, Anker AD, Bauer JM, Bernabei R, et al. Frailty Consensus: A Call to Action. Journal of the American Medical Directors Association. 2013; 14(6):392-397.

3. Fried LP, Tangen CM, Walston J, Newman AB, Hirsch C, Gottdienner J, et al., Cardiovascular Health Study Collaborative Research Group. Frailty in older adults: Evidence for a phenotype. J Gerontol A Biol Sci Med Sci. 2001; 56:M146-156.

4. Romero RL, Abizanda SP. Frailty as a predictor of adverse episodes in epidemiological studies. Rev Esp Geriatr Gerontol. 2013;48:285-289.

5. Ensrud KE, Ewing SK, Taylor BC, KL, Fink HA, Cawthon PM, Stone KL. Comparison of 2 frailty indexes for prediction of falls, disability fractures, and death in older women. Arch Intern Med. 2008; 168:382-389.
6. García-González JJ, García-Peña C, Franco-Marina F, Gutiérrez-Robledo LM. A frailty index to predict the mortality risk in a population of senior Mexican adults. BMC Geriatrics. 2009;9:47. doi:10.1186/1471-2318-9-47.

7. Aguilar-Navarro, S. G., Amieva, H., Gutiérrez-Robledo, L. M., \& Avila-Funes, J. A. (2015). Frailty among Mexican community-dwelling elderly: a story told 11 years later. The Mexican Health and Aging Study. Salud publica de Mexico, 57 Suppl 1(0 1), S62-S69.

8. Samper-Ternent, R., Reyes-Ortiz, C., Ottenbacher, K.J. Cano CA. Frailty and sarcopenia in Bogotá: results from the SABE Bogotá Study. Aging Clin Exp Res. 2017 Apr;29(2): 265-272.

9. Calado, Larissa Barradas, Ferriolli, Eduardo, Moriguti, Júlio César, Martinez, Edson Zangiacomi, \& Lima, Nereida Kilza da Costa. (2016). Frailty syndrome in an independent urban population in Brazil (FIBRA study): a cross-sectional populational study. Sao Paulo Medical Journal, 134(5), 385-392. Epub September 19, 2016.

10. Pérez-Zepeda MU Cesari M García-Peña C. Predictive value of frailty indices for adverse outcomes in older adults. Rev Invest Clin. 2016; 68:92-98.

11. Picado-Ovares JE, Barrientos-Calvo IC, Morales-Martinez F, Alejandro SandíJirón. Frailty in the elderly population of Costa Rica. Jpn J Med. 2018, 4:33-37.

12. Mata Da, Figueiredo. Perez da Silva P., Cordeiro de Andrade, Keitty Regina, Godoy Figuereido, AC, Tolentino Silva, M, et al. A. Prevalence of Frailty in Latin America and the Caribbean: A Systematic Review and Meta-Analysis. Ed. Jo Thompson Coon. PLoS ONE. 2018; 11.8: e0160019.

13. Woods N, LaCroix A, Gray S, Aragaki A, Brunner RL, Masaki K, Murray A, Newman AB. Frailty: Emergence and consequences in women aged 65 and older in the WHIOS. J Am Geriatr. Soc. 2005; 53:1321-1330.

14. Avila-Funes, J. A, Helmer, C, Amieva, H, Barberger-Gateau, P, Le Goff, M, Ritchie, K, Dartigues, J. F. (2008). Frailty among community-dwelling elderly people in France: the three-city study. The journals of gerontology. Series A, Biological sciences and medical sciences, 63(10), 1089-1096. doi:10.1093/ gerona/63.10.1089.

15. Song X, Mitnitski A, Rockwood K. Prevalence and 10-year outcomes of frailty in older adults in relation to deficit accumulation. J Am Geriatr Soc. 2010; 58:681-687.

16. Rockwood K, Howlett SE, MacKnight C, Beattie BL, Bergman H, Hébert R, et al. Prevalence, attributes and outcomes of fitness and frailty in community dwelling older adults: Report from the Canadian study of health and aging. J Gerontol A Biol Sci Med Sci. 2004; 59:1310-1317.

17. Yu P, Song X, Shi J, Mitnitski A, Tang Z, Fang X, Rockwood K. Frailty and survival of older Chinese adults in urban and rural areas: Results from the Beijing Longitudinal Study of Aging. Arch Gerontol Geriatr. 2012; 54:3-8.

18. Bandeen-Roche K, Xue OL, Ferrucci L, Walston J, Guralnik JM, Chaves P, Zeger SL, et al. Phenotype of frailty: Characterizacion in the women's health and aging studies. J Gerontol A Biol Sci Med Sci. 2006; 61:262-266.

19. Buchman AS, Wilson RS, Bienias JL, Bennett DA. Change in frailty and risk of death in older persons. Exp Aging Res. 2009;35:61-82.

20. Abizanda P, Romero L, Sánchez-Jurado PM, Martínez-Reig M, Gómez-Arnedo L, Alfonso SA. Frailty and mortality, disability and mobility loss in a Spanish cohort of older adults: The FRADEA Study. Maturitas. 2013;74:54-60.

21. Solfrizzi V, Scafato E, Frisardi V, Sancarlo D, Seripa D, Logroscino G, et al. Italian Longitudinal Study on Aging Working Group. Frailty syndrome and allcause mortality in demented patients: The Italian Longitudinal Study on Aging. Age (Dordr). 2012;34:507-517.

22. Ensrud KE, Ewing SK, Cawthon PM, Fink HA, Taylor BC, Cauley JA, et al. Osteoporotic Fractures in Men Research Group. A comparison of frailty indexes for the prediction of falls, disability, fractures, and mortality in older men. J Am Geriatr Soc. 2009; 57:492-498.

23. Al Snih S, Graham JE, Ray LA, Samper-Ternent R, Markides KS, Ottenbacher KJ. Frailty and incidence of activities of daily living disability among older mexican americans. J Rehabil Med. 2009;41:892-897.

24. Rothman M, Leo-Summers L, Gill TM. Prognostic significance of potential frailty criteria. J Am Geriatr Soc. 2008; 56:2211-2216. 